\title{
Prevalence of gastrointestinal parasites in Faisalabad and comparative efficacy of Ivermectin and Albendazole
}

Nadeem Iqbal $^{1}$, Syed Ashar Mahfooz ${ }^{1}$, Muhammad Kasib Khan ${ }^{2}$, Hafiz Muhammad Rizwan ${ }^{2,3 *}$, Asghar Abbas ${ }^{2}$, Rao Zahid Abbas ${ }^{2}$ and Ambreen Ashar ${ }^{4}$

1. Department of Clinical Medicine and Surgery, Faculty of Veterinary Science, University of Agriculture, Faisalabad-Pakistan

2. Department of Parasitology, Faculty of Veterinary Science, University of Agriculture, Faisalabad-Pakistan

3. Quality Operations Laboratory, University of Veterinary and Animal Sciences, Lahore-Pakistan

4. Department of Chemistry, Government College Women University Faisalabad-Pakistan

*Corresponding author's email: drrizwan1174@gmail.com

Citation

Nadeem Iqbal, Syed Ashar Mahfooz, Muhammad Kasib Khan, Hafiz Muhammad Rizwan, Asghar Abbas, Rao Zahid Abbas and Ambreen Ashar. Prevalence of gastrointestinal parasites in Faisalabad and comparative efficacy of Ivermectin and Albendazole. Pure and Applied Biology. Vol. 6, Issue 2, pp499-504. http://dx.doi.org/10.19045/bspab.2017.60049

Received: 22/12/2016 Revised: 20/03/2017 Accepted: 26/03/2017

Online First: 30/03/2017

\section{Abstract}

Current study was conducted to evaluate the prevalence rate of gastrointestinal tract (GIT) parasites of cats in Faisalabad and check the comparative efficacy of Ivermectin and Albendazole. A total of 384 fecal samples of cats were collected randomly from different government and private clinics of district Faislabad. Ivermectin and Albendazole were used for the treatment against the GIT parasites. After clinical examination, 70 positive cats with GIT parasites were grouped as follows: group $A(n=30)$ which was treated with graded doses of ivermectin (merial), similarly group B $(n=30)$ treated with graded doses of albendazole (zental) and group $\mathrm{C}(\mathrm{n}=10) \mathrm{kept}$ as a control. Fecal samples were processed in postgraduate laboratory, Department of Clinical Medicine and Surgery, University of Agriculture, Faisalabad. Quantitative fecal examination was performed to observe the egg per gram of feces before and after treatment. The percentage of infection was found higher in female cats $33.33 \%$ than male $24.44 \%$. The prevalence in adults and kittens was recorded as $24.10 \%$ and $42.45 \%$ respectively. T. cati was found more prevalent with the infection rate of $7.03 \%$ followed by T. leonina, A. duodenalis, A. abstrus, T.Taeniaformimus, D. caninum, A. tubaeforme and T. gondii with the infection rate of 5.4, 4.1, 3.7, 2.6, 2.3, 2.3 and $1.8 \%$ respectively. Comparatively ivermectin showed more significant results against GIT parasites of cats than albendazole.

Keywords: Ivermectin; Albendazole; Prevalence; GIT parasites; Cats; EPG

Introduction

Domestic cats (Felis catus) have originated from wild cats (Felis silvestris) which are species of Africa and Europe. Generally both cats poses approximately same behavior i.e. hunting but now domestic cat is consider as distinguished specie. Companionship of human and cat has been 
for the last 9500 years [1-12]. Gastrointestinal (GIT) parasitic infestation is the most common cause of morbidity in the domestic cats. Both wild and domestic cats play a vital role in the transmission of these parasites [2]. Cats are infected by different types of parasites i.e. round worms ( $T$. cati and $T$. leonina) which are creamy colored, 3-5 inch long and cause blockage of small intestine. Kittens are more susceptible than adults. They transmitted by ingestion of worm eggs or larva. Similarly, hook worms (species of Ancylostoma) have cylindrical body of 0.5 inch in length. They penetrate into intestine and cause anemia and death in untreated cases. Tapeworms (cestodes) have flat segmented body and their eggs can be observed near rectum, tail and in feces but infection is rare.

Different types of protozoa can also cause severe damage to intestinal tract i.e. Isospora felis causes coccidiosis and damages the mucosa of intestine, resulting in diarrhea in kittens but less common in adults. Giardia is present in small intestine and causes chronic or acute diarrhea which may be continuous or intermittent in nature. $T$. gondii is present in small intestine and transmitted vertically as well as by ingestion of infected material with sporulated oocyst and causes Toxoplasmosis. The prevalence of GIT parasites are associated with environmental condition, geography, cat population (including feral, household and stray etc.) and adoption of prophylaxic measures [3-13].

Different anthelmintics are effective against GIT parasites of cat i.e. Vermix (diphenthane-yo $0.1 \mathrm{gm}+$ methylbenzene 0.1 cc) has good efficacy against hook worm, ascarid and tape worm but not for Physaloptera [4-12]. Nitroscanate has good response against $T$. cati and A. tubaeforme and paste of paraziquental $0.34 \%$ and febental $3.4 \%$ is mixed in feed of cat. This paste is effective against specie of Taenia and T. cati [5].The ivermectin and albendazole are most common locally used anthelmintics. Ivermectin also shows good response against arthropods, nematode as well as plant parasites [6]. The effect of ivermectin varies from specie to specie and inters individuals. This anthelmintic is lipophilic, insoluble in water but soluble in organic substances. It has no effect on the breeding performance of animals. Pharmacokinetics of ivermectin is influenced by route of administration and formulation. Subcutaneous (S/C) injection of ivermectin shows good response than oral and topical route. Ivermectin absorbs slowly through S/C tissues and persists for long time [7]. Ivermectin has inhibitory potential for GABA associated parasitic nerve transmission. Moreover, use of ivermectin caused paralysis of pharyngeal muscles which consequently caused the flaccid paralysis of nematode [8].

Albendazol which belongs to benzimidazole class has good efficacy against nematode, fluke, cestode, lung worm and protozoa's. Benzimidazole paralyzed the worm by tubulin binding (protein structure of microtubule). Hence block of microtubules causes problem in uptake of glucose. In this way energy mechanism is stopped which causes paralysis and death of worm. This study was conducted to evaluate the prevalence of the GIT parasites in cats and check the comparative efficacy of ivermectin and albendazole.

\section{Materials and methods Collection of samples}

For examination of GIT parasites, fecal samples of 384 cats were collected randomly from clinic of Clinical Medicine and Surgery (C.M.S), Civil Veterinary Hospital (C.V.H), Medina town veterinary hospital, Juj wala veterinary hospital and private clinic (Pets Health Center) of Faisalabad. The samples were properly labelled for identification and transported to the the 
postgraduate laboratory, Department of Clinical Medicine and Surgery, University of Agriculture, Faisalabad.

\section{Chemotherapy}

Samples were examined before and after administration of ivermectin and albendazole. Firstly fecal sample examined by direct method if sample was positive for GIT parasite then chemotherapy performed. After that Mcmaster technique performed at $0^{\text {th }}, 7^{\text {th }}$ and $21^{\text {th }}$ day of post treatment. Clinical signs vomiting, chronic diarrhea, poor quality and rough hair coat, swollen abdomen, less active of body, poor digestion of food, unthrifty, abdominal pain, partial anorexia, sometime blood in stool and anemia were observed. To evaluate the efficacy of ivermectin and albendazole against GIT parasites, a total of 70 cats positive with GIT parasites were randomly selected and grouped as follows. Group A-1, A-2 and A-3 treated with graded doses of ivermectin subcutaneously @ 150,250 and $300 \mu / \mathrm{kg}$ respectively $(\mathrm{n}=30)$ (Table 1$)$. Group B-1, B-2 and B-3 treated with graded doses of albendazole orally @ 30,35 and $40 \mathrm{mg} / \mathrm{kg}$ respectively $(\mathrm{n}=30)$ (Table 2$)$. And group $\mathrm{C}$ was kept in control group to compared the normal parameters $(n=10)$.

Table 1. Comparison of means of ivermectin (merial)

\begin{tabular}{|l|c|}
\hline Ivermectin doses & Mean \pm SE \\
\hline $150 \mu \mathrm{g} / \mathrm{kg}$ & $57.6 \pm 1.968 \mathrm{C}$ \\
\hline $250 \mu / \mathrm{kg}$ & $86.1 \pm 2.373 \mathrm{~B}$ \\
\hline $300 \mu / \mathrm{kg}$ & $94.3 \pm 1.700 \mathrm{~A}$ \\
\hline
\end{tabular}

Means sharing similar letters are statistically non-significant $(\mathrm{P}>0.05)$. The effective doses against the GIT parasites were 300,250 and $150 \mu \mathrm{g} / \mathrm{kg}$ with the mean reduction of eggs $94.3,86.1$ and $57.6 \%$ respectively

Table 2. Comparison of means of Albendazole (zental)

\begin{tabular}{|l|c|}
\hline Albendazole doses & Mean \pm SE \\
\hline $30 \mathrm{mg} / \mathrm{kg}$ & $50.7 \pm 4.182 \mathrm{C}$ \\
\hline $35 \mathrm{mg} / \mathrm{kg}$ & $72.8 \pm 1.812 \mathrm{~B}$ \\
\hline $40 \mathrm{mg} / \mathrm{kg}$ & $86.3 \pm 1.391 \mathrm{~A}$ \\
\hline
\end{tabular}

Means sharing similar letters are statistically non-significant $(\mathrm{P}>0.05)$. The effective doses against the GIT parasites were 40,35 and $30 \mathrm{mg} / \mathrm{kg}$ with the mean reduction of eggs $86.3,72.2$ and $50.5 \%$ respectively

\section{Statistical analysis}

Data analyzed through analysis of variance technique and significant difference was done using least significant difference (LSD) test at 5\% level of significance. T-test was applied for comparison between means.

\section{Results}

The sample was considered as a positive on finding the one or more eggs and parasites. Animal data such as sex, breed and age was recorded. Egg or parasitic identification was made on the basis of size and morphology. It was observed that cats usually harbor different kind of parasites due to improper care and unhygienic conditions by the owner. To check the rate of prevalence of GIT parasites in cats selected areas randomly visited during period from December 2015 to April 2016.

Out of 384 cats only 112 cats were positive for GIT parasites i.e. (round worm, tape worm, hook worm and protozoa) and the overall prevalence found was $29.16 \%$. Specie wise $T$. cati was found more prevalent with the infection rate of $7.03 \%$ followed by $T$. leonina, A.duodenalis, $A$. abstrusus, T. Taeniaformimus, D. caninum, $A$. tubaeforme and $T$. gondii with the infection rate of 5.46, 4.16, 3.38, 2.6, 2.34, 2.34 and $1.82 \%$ respectively. It was 
observed than male cats were more resistant to GIT parasites than female cats due to resistant of body and mucosal immunity of intestine. Figure 1 shows the comparison of effect of ivermectin and albendazole on prevalence of GIT parasites in cats. The prevalence rate was high in female $33.33 \%$ than male $24.44 \%$. Kittens were more sensitive to GIT parasites than adults due to lack of mucosal immunity. Adults were resistant due to natural tendency to cleanliness and private living space. The rate of prevalence of GIT parasites were high in kittens $42.45 \%$ than adult $24.10 \%$. It was also noticed that the 92 cats which were positive for GIT parasites out of 112 cats, infected due to improper management, poor feeding and unhygienic condition. The rate of prevalence was high $(82.14 \%)$ due to unhygienic conditions and improper management. The monthly prevalence was found in December (17.94\%), January $(18.86 \%)$, Febrauary $(22.36 \%)$, March (25.92\%) and April (42.22\%). During the April and March the prevalence rate was high due to climatic conditions of Faisalabad, Pakistan being conducted for maturation and growth of parasites of GIT.

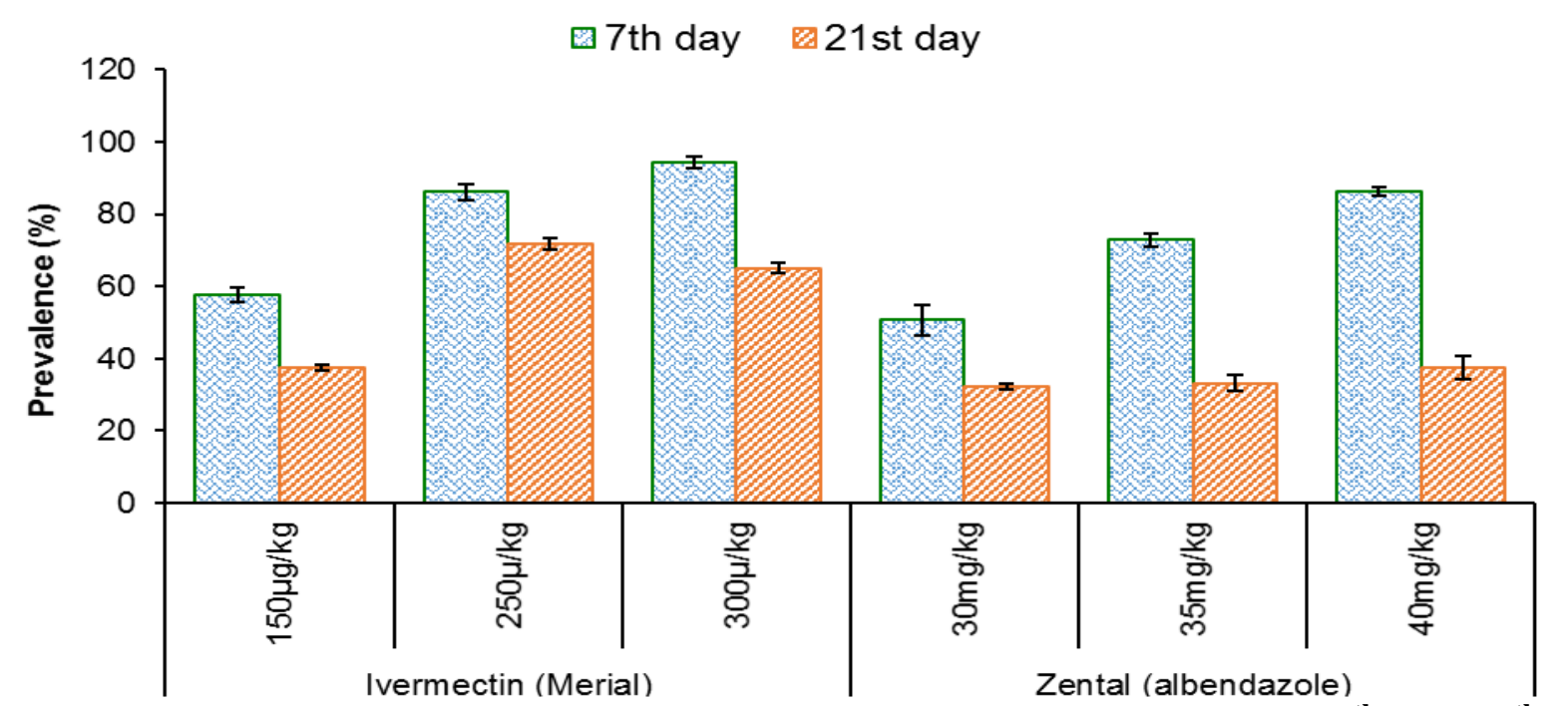

Figure 1. Comparison $b / w$ graded doses of ivermectin and albendazole at $7^{\text {th }}$ and $21^{\text {th }}$ day of post treatment

\section{Discussion}

The gastrointestinal parasites like T. cati, A. duodenale, $T$. gondii, $D$. caninum, $G$. duodenalis, T. taeniaformimus, T. leonine and $A$. tubaeforme are thought to be common intestinal parasites of domestic cats. There are several factors to involved in the parasitic infestation of cats i.e. unhygienic condition, decrease the feed quality, poor management, decrease in the mucosal immunity. Climatic factor also play a major role in the prevalence of GIT parasites. Due to parasitic infestation of GIT cats usually suffer from vomiting, diarrhea, rough hair coat, poor digestion of food, unthrifty, abdominal pain, partial anorexia, sometime blood in stool and anemia [13]. In the present study, the findings are according with the results of Memon et al. [1]. They reported $24 \%$ overall prevalence rate of GIT parasites in cats. Their results showed that the prevalence rate was higher in female (28\%) than male (20\%) and kittens were more susceptible (30\%) than adults $(21.42 \%)$. In the parallel to results of present study reported that the prevalence of GIT 
parasites in the domestic cats was $(34.3 \%)$ and $T$. cati $(20.3 \%)$ were observed most common. Arbabi and Hossein (2008) recorded that the prevalence of GIT parasites was higher in male $(59.3 \%)$ than female $(40.7 \%$ ) [9]. In another study it was found that the nematode ( $T$. cati) was most prevalent parasite than other GIT parasites [10]. Similarly, $63.4 \%$ sero prevalence was found in stray cats in Madrid [11].

In the light of above findings, it was suggested and concluded that care is being taken by the owner for the maintained the health status of cat. Cats usually infected by GIT parasites due to improper management and unhygienic condition. Infected cats act as a source of infection for others. Among the feline GIT parasites i.e. T. cati, A. duodenalis, A. tubaeforme, T. gondii and $G$. deodenalis have zoonotic potential. The zoonotic character parasites found in this study must serve to alert to the physician and public health agencies. It was also observed that ivermectin showed significant results against the GIT parasites than albendazole.

The similar type of frequency of gastrointestinal parasites and protozoa was observed in 502 cats of Brazil, between 2005 and 2014 which shows that prevalence of parasites is increasing in the felines and control measures should be adopted against these parasites [12]. In another study prevalence of gastrointestinal parasites was observed in city of Belgrade (Serbia). All helminthosis diagnosed in the research possess a zoonotic potential. The highest prevalence of toxocarosis was established in dogs younger than 1 year $(19,32 \%)$ and in cats oldern than 8 years $(27.27 \%)$. Ancylostomatidosis was diagnosed with the highest prevalence in samples from animals between 1 and 8 years old (16.66\% of dogs and $22.22 \%$ of cats) [13].

\section{Conclusion}

Present study showed that the overall prevalence of gastero intestinal parasites was was $29.16 \%$ in cat. Specie wise T.cati was found more prevalent with the infection rate of $7.03 \%$ followed by $T$. leonina, A.duodenalis, A. abstrusus, $\quad T$. Taeniaformimus, D. caninum, A. tubaeforme and $T$. gondii respectively. It was observed than male cats were more resistant to GIT parasites than female cats due to resistant of body and mucosal immunity of intestine.

\section{Authors' contribution}

Conceived, designed and performed the experiment: N Iqbal, SA Mahfooz, \& MK Khan, Analyzed the data: HM Rizwan, A Abbas, RZ Abbas \& A Ashar, Wrote the paper: HM Rizwan, A Abbas, RZ Abbas \& A Ashar.

\section{Acknowledgments}

The authors acknowledge Veterinary clinic of clinical medicine and surgery (CMS) department the University of Agriculture, Faisalabad for its support in the execution of this research study.

\section{References}

1. Memon AH, Gadahi JA, Bhotto B, Arijo AG, Akhtar N \& Memon MR (2013). Prevalence of gastrointestinal parasites in Felis catus. Veterinaria 1(1): 21-23.

2. Miro G, Montoyaa A, Jimenezb S, Frisuelosa C, Mateoa M \& Fuentesc I (2004). Prevalence of antibodies to Toxoplasma gondii and intestinal parasites in stray, farm and household cats in Spain. Vet Parasitol 126 (3): 249-255.

3. Mircean V, Titilincu A \& Vasile C (2010). Prevalence of endoparasites in household cat (Felis catus) populations from Transylvania (Romania) and association with risk factors. Vet Parasitol 171(1-2): 163-166.

4. Burch GR \& Blair HE (1950). Vermiplex, an anthelmintic for cats. North Am Vet 31(5): 329-333. 
5. Corwin RM, Pratt SE \& Muccurdy HD (1984). Anthelminntic effect of febental/paraziquental paste in dogs and cats. Am J Vet Res 45 (1): 154-155.

6. Barragry TB (1987) A review of the pharmacology and clinical uses of ivermectin. Can Vet J 28 (5): 512-517.

7. Canga AG, Prieto AMS, Liebana MJD, Martinez NF, Vega MS \& Vieitez JJG (2009). The pharmacokinetics and metabolism of ivermectin in domestic animal species. Vet $J 179$ (1): 25-37.

8. Geary TG, Sims SM, Thommas EM, Vanover L, Davis JP, Winterrowd CA, Klein RD, Ho NFH \& Thompson DP (1993). Haemonchus contortus ivermectin induced paralysis of pharynx. Exp Parasitol 77 (1): 88-96.

9. Arbabi M \& Hossein H (2008). Gastrointestinal parasites of stray cats in Kashan. Trop Biomed 26 (1): 16-22.

10. Zibaei M, Seyed MS \& Bahador S (2007). Prevalence of Toxocara cati and other intestinal helminthes in stray cats in Shiraz, Iran. Trop Biomed 24 (2): 39-43.

11. Alonso A, Quintanilla GA, Rodri MAG, Bueno PJ, Ortega LMM \& Miro G (1997). Seroprevalence of Toxoplasma gondii infection in vagrant cats in the area of Madrid. Acta Parasitol 4 (1): 12.

12. Gennari SM, Juliana Isabel Giuli da Silva Ferreira JIGS, Pena HFJ, Labruna MB \& Azevedo SS (2016) Frequency of gastrointestinal parasites in cats seen at the University of São Paulo Veterinary Hospital, Brazil. Braz J Vet Parasitol 25 (4): 423-428.

13. Ilić T, Kulišić Z, Antić N, Radisavljević K \& Dimitrijević S (2017). Prevalence of zoonotic intestinal helminths in pet dogs and cats in the Belgrade area. $J$ App Anim Res 45 (1): 204-208. 